\title{
MITIGASI BENCANA BERDASARKAN NILAI SHEAR STRAIN TANAH AKIBAT GEMPA BUMI PADA TEMPAT PEMBUANGAN AKHIR (TPA) NGIPIK, GRESIK
}

\author{
Siti Nurlita Fitri ${ }^{*}$, Ria Asih Aryani Soemitro dan Dwa Desa Warnana ${ }^{3}$ \\ 1Dosen, Program Studi Teknik Sipil, Fakultas Teknik, Universitas Sebelas Maret \\ 2 Dosen, Departemen Teknik Sipil, Fakultas Teknik Sipil, Perencanaan, Dan Kebumian, \\ Institut Teknologi Sepuluh Nopember \\ ${ }^{3}$ Dosen, Departemen Teknik Geofisika, Fakultas Teknik Sipil, Perencanaan, Dan \\ Kebumian, Institut Teknologi Sepuluh Nopember \\ *Korespondensi: sitinurlitafitri@staff.uns.ac.id
}

\begin{abstract}
Ngipik Landfill located in Gresik, East Java has a several active fault. Due to the condition, this area has high possibility of earthquake prone area. There is no bottom layer construction to prevent and control the leachate's spread. This study aim to analyze the earthquake hazard map for the region based on the values of ground shear strain. The data was conducted by microtremor measurement and Plaxis modeling. The result of this study shows the shear strain value range between $3.5 \times 10^{-3}$ to $12.5 \times 10^{-3}$. The highest value is around the east and west-north area and indicated the high risk of damage under ground motion. The output of the research must consider as preliminary site mitigation of Ngipik Landfill.
\end{abstract}

Keywords : Landfill, Micromtremor, Seismic, Shear strain, Site effect

\section{PENDAHULUAN}

Tempat pembuangan akhir (TPA) Ngipik merupakan TPA yang berada di Kabupaten Gresik, Jawa timur. TPA ini terletak pada area perindustrian dengan kapasitas yang hampir penuh dimana ada 2 timbunan sampah yang telah terdekomposisi dengan tinggi mencapai 10 dan $12 \mathrm{~m}$. TPA menggunakan sistem open dumping pada sistem pengolahannya, dimana pada sistem ini tidak adanya clay liner (lapisan lempung kedap air dengan ketentuan tertentu) untuk mencegah aliran lindi masuk kedalam tanah dan mencemari air tanah dan daerah sekitarnya. Selain tidak adanya sistem liner yang memadai, pengolahan air lindi beserta limbah lainnya juga tidak tertata secara baik.

Lindi adalah cairan yang dihasilkan oleh sampah yang telah terdekomposisi, yang tersuspensi dan terekstraski oleh reaksi sampah. Lindi mengandung beberapa kandungan kimia didalamnya, seperti $\mathrm{Ca}, \mathrm{CaCO}_{3}, \mathrm{Mg}, \mathrm{K}, \mathrm{Na}, \mathrm{Fe}$, $\mathrm{Si}, \mathrm{Al}, \mathrm{Cl}, \mathrm{SO}_{4}$ dan Amonia. Kandungan bahan kimia inilah yang akan membahayakan bagi daerah sekitar apabila penyebaran dan pengolahan lindi tidak dikelola dengan benar.

Gresik adalah daerah dengan kondisi tanah terdiri dari endapan alluvial, yang mana wilayah dengan kondisi geologi berupa endapan alluvial dan tuff mempunyai potensi besar terhadap efek gempa. Hal ini disebabkan karena efek dari nilai amlifikasi tanah dasar serta interkasi getaran tanah dan bangunan akibat dari gempa bumi. Selain itu juga terdepat beberapa persebaran riwayat kegempaan yang terjadi didaerah sekitar Gresik. Beberapa data terbaru tentang pergerakan aktif beberapa sesar di Jawa timur seperti Sesar Kendeng yang merupakan sesar aktif dan terbentang dari Jawa tengah hingga ke Jawa timur juga menunjukan strain rate sebesar $1.93 \mathrm{~mm} /$ tahun, $0.90 \mathrm{~mm} / \mathrm{tahun}$, dan $0.60 \mathrm{~mm} /$ tahun untuk segmen barat, timur dan ekstensinya. [1]

Setiap Infrastruktur sipil tidak lepas 
kaitannya dengan ketahanan terhadap gempa, termasuk tempat pembuangan akhir (TPA). Salah satu contoh kerusakan yang terjadi akibat gempa di TPA California yang menyebabkan adanya displacement di bawah permukaan, serta Gempa Kobe tahun 1995 yang membuat beberapa TPA di California memberikan kontribusi besar dalam pencemaran air tanah, dimana adanya nilai regangan yang besar di lapisan bawah sehingga mengidentifikasikan kerusakan sistem liner dibawah timbunan sampah. [2]

TPA Ngipik adalah TPA satu-satunya di Kabupaten Gresik, dan tidak memungkinkan untuk dibuat TPA baru, walaupun pada kenyataannya TPA ini masih menggunakan sistem pengolahan lindi yang masih belum dikelola secara baik dan dapat membahayakan bagi daerah sekitar. Selain itu, Kabupaten Gresik juga mempunyai beberapa faktor rawan akibat bahaya gempa. Oleh karna itu perlu adanya analisis tentang efek tapak lokal akibat gempa yang berupa nilai shear strain yang mengindikasikan kerentanan tanah didaerah sekitar TPA Ngipik untuk dapat dijadikan langkah awal untuk mengantisipasi bahaya gempa apabila akan dilakukannya pengembangan terhadap TPA Ngipik kedepannya.

\section{TINJAUAN PUSTAKA}

\subsection{Tempat Pembuangan Akhir}

Tempat Pembuangan akhir merupakan salah satu infrastuktur sipil guna berlangsungnya kegiatan untuk memproses serta mengembalikan sampah ke lingkungan secara aman. Selain itu TPA juga diharapkan dapat menyediakan pengolahan air lindi yang baik sehingga tidak menimbulkan bahaya bagi daerah sekitar.

Metode pengolahan sampah secara umum dibagi menjadi 2 kelompok yaitu Metode Sanitary landfill dan Metode Open Dumping. Metode Sanitary landfill dilakukan dengan menumpuk sampah secara berlapis-lapis, kemudian diolah seperti dilakukannya pemadatan, perataan dan diakhir operasi akan ditutup dengan tanah penutup. Metode ini menggunakan beberapa lapisan untuk mencegah lindi masuk dan meresap kedalam tanah. Sedangkan Metode Open dumping yaitu metode pengolahan sampah yang dilakukan secara terbuka. Dibandingkan dengan Sanitary landfill metode ini lebih menimbulkan masalah disekitar TPA karna tidak mempunyai lapisan kedap air untuk mencegah lindi mencemari daerah sekitarnya.

\subsection{Penyelidikan dan Analisis Mikrotremor}

Mikrotremor merupakan alat yang menggunakan metode horizontal-to-vertical ratio (HVSR) dalam rangka mendapatkan nilai amplifikasi dan frekuensi tanah. Selain itu metode ini juga dapat digunakan untuk mengukur indeks kerentanan serta mengetahui efek tapak lokal kegempaan dari suatu wilayah sebagai mitigasi awal.[3]

Indeks kerentanan tanah merupakan gambaran awal tentang kerentanan lapisan tanah terhadap deformasi ketika gempa. Nilai ini dapat memberikan infromasi mengenai potensi tingkat goncangan tanah karena gempa. Secara teoritis Indeks kerentanah tanah dapat dicari dengan persamaan berikut :

$$
K_{g}=\frac{A m^{2}}{F_{0}}
$$

Dimana :

$\mathrm{Kg}=$ Indeks Kerentanan tanah

$\mathrm{A}_{\mathrm{m}}=$ Amplifikasi

$\mathrm{F}_{0}=$ Frekuensi Natural

Selain indeks kerentanan tanah, hal penting lain yang dapat dijadikan acuan sebagai mitigas awal akibat tapak lokal kegempaan adalah nilai shear strain. Shear strain secara umum didefinisikan sebagai kemampuan metaterial penyusun tanah yang dapat saling meregang dan bergeser ketika terjadinya gempa bumi. Nilai shear strain melalui analisis mikrotremor dapat dicari menggunakan persamaan:

$$
y=A_{m} \frac{\delta}{H}
$$

Dimana :

$\delta=$ seismic displacement dari dasar batuan (bedrock)

$\mathrm{H}=$ Tebal lapisan permukaan

Deformasi akibat gempa bumi akan menimbulan besarnya regangan dari suatu tanah. Regangan inilah yang dapat dijadikan acuan terhadap tingkat kerusakan akibat gempa. Tabel hubungan antara nilai shear strain dan sifat dinamis tanah diberikan pada Tabel 1.

Dari Tabel 1 dapat dilihat beberapa fenomena berdasarkan nilai shear strain tanah, dimana dengan nilai shear strain berkisar $10^{-4}$ saja sudah menimbulkan terjadinya retakan 
(crack) dan penurunan pada kontruksi bawah.

Tabel 1. Hubungan Antara Nilai Shear Strain dan Sifat Dinamis Tanah

\begin{tabular}{|c|c|c|c|}
\hline $\begin{array}{c}\text { Ukuran } \\
\text { Strain }(\gamma)\end{array}$ & Fenomena & \multicolumn{2}{|c|}{ Sifat dinamis } \\
\hline $10^{-6}$ & \multirow[t]{2}{*}{ Getaran } & \multirow{2}{*}{\multicolumn{2}{|c|}{ Elastis }} \\
\hline $10^{-5}$ & & & \\
\hline $10^{-4}$ & \multirow{2}{*}{$\begin{array}{c}\text { Crack, } \\
\text { penurunan }\end{array}$} & \multirow{2}{*}{\multicolumn{2}{|c|}{ Elastoplastis }} \\
\hline $10^{-3}$ & & & \\
\hline $10^{-2}$ & \multirow{2}{*}{$\begin{array}{l}\text { Longsor, } \\
\text { likuifaksi }\end{array}$} & \multirow[t]{2}{*}{ Collapse } & \multirow{2}{*}{$\begin{array}{c}\text { Efek } \\
\text { berulang }\end{array}$} \\
\hline $10^{-1}$ & & & \\
\hline
\end{tabular}

\section{METODE PENELITIAN}

\subsection{Gambaran Umum Penelitian}

Penelitian ini menggabungkan data sekunder yang didapatkan dari penelitian sebelumnya, dan data primer dilapangan. Kemudian data tersebut digabungkan untuk dilakukan simulasi dengan menggunakan program bantu. Simulasi bertujuan untuk melihat perilaku dari timbunan sampah dan area sekitar TPA Ngipik terutama yaitu pada bagian bawah permukaan timbunan terhadap kerentanan yang terjadi akibat gempa.

Tinjauan kerentanan tanah terhadap gempa dilihat berdasarkan hasil nilai shear strain yang diperoleh dari simulasi dengan program bantu. Nilai shear strain itu kemudian dipetakan sehingga menjadi peta area kerentanan tanah di TPA Ngipik sebagai langkah mitigasi bencana dalam perencanaan pengembangan TPA kedepannya.

\subsection{Analisis Mikrotremor}

Data sekunder hasil survey mikrotremor yaitu berupa data pengujian mikrotremor sebanyak 28 titik. Dari pengujian awal ini didapatkan hasil berupa nilai amplifikasi yaitu sebesar 2.0-7.5 serta nilai frekuensi natural sebesar 1.1-3.65 Hz. [5]

Dari nilai data sekunder berupa amplifikasi dan frekuensi natural maka dapat diketahui menggunakan rumusan empiris nilai shear strain dari analisis mikrotremor untuk daerah TPA Ngipik.

\subsection{Analisis Topografi}

Dilakukan pengujian secara langsung dilapangan untuk mendapatkan data topografi dari timbunan sampah. Data primer kemudian dievaluasi sesuai dengan elevasi menggunakan program bantu google earth untuk tiap titik yang ditinjau. Kemudian dilakukan pembuatan peta kontur menggunakan program bantu dari kawasan TPA Ngipik.

\subsection{Analisis Pemodelan dan Pembuatan Peta Sebaran Kerentanan Tanah}

Setelah didapatkan hasil dari topografi serta gemoteri dari timbunan, maka dilakukan pemodelan sesuai dengan data geometri yang ada. Pemodelan dilakukan menjadi 5 kali pemodelan dengan geometri yang berbeda.

Simulasi pemodelan menggunakan program bantu. Analisis pemodelan dengan memasukan beban gempa sesuai dengan Peak Ground Acceleration (PGA) dari data di Kabupaten Gresik. Simulasi ini bertujuan untuk mendapatkan nilai shear strain pada geometri timbunan, terutama dibagian bawah permukaan timbunan.

\section{HASIL DAN PEMBAHASAN}

\subsection{Hasil Analisis Mikrotremor}

Hasil nilai awal mikrotremor kemudian diubah menggunakan Persamaan (2) untuk mendapatkan nilai shear strain dari berbagai titik. Dari hasil nilai tersebut kemudian dibuatlah peta persebaran nilai shear strain pada daerah di sekitar TPA Ngipik. Peta hasil persebaran diberikan pada Gambar 1.

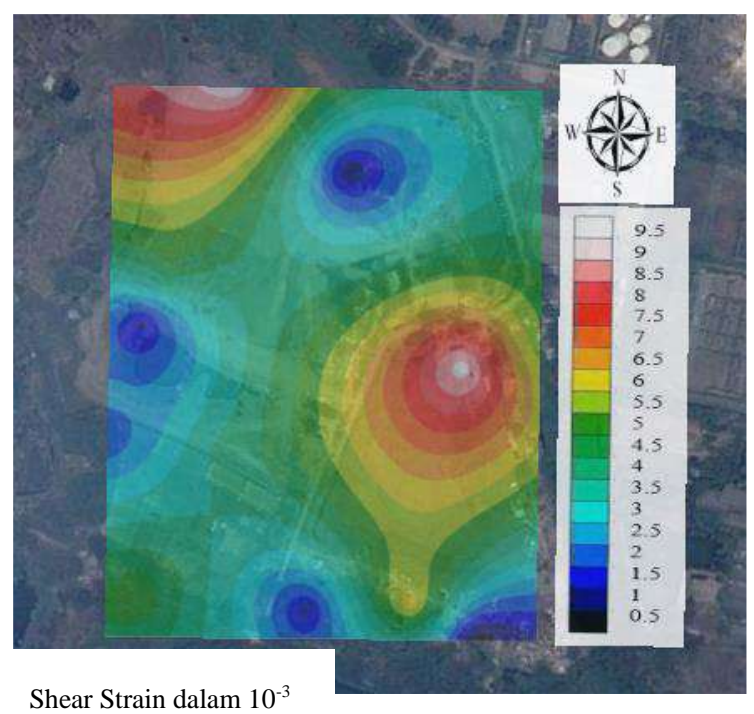

Gambar 1. Sebaran Nilai Shear Strain

Dari Gambar 1 dapat diketahui bahwa persebaran nilai shear strain berkisar antara $0.5 \times 10^{-4}-9.5 \times 10^{-3}$. Menurut Tabel 1, dengan nilai shear starin tersebut, menandakan 
terjadinya fenomena crack atau penuruan, dengan sifat dinamis elastoplastis dengan efek berulang. Artinya, semakin tinggi nilai shear strain yang dihasilkan, maka semakin tinggi pula tingkat kerentanan terhadap bahaya gempa. Nilai shear starin tertinggi berada pada daerah timur dari TPA Ngipik, hal ini terjadi dikarenakan daerah tersebut mempunyai nilai amplifikasi yang lebih besar serta kedalaman lapisan sedimen bedrock yang cukup tipis dari daerah lain disekitarnya.

\subsection{Hasil Analisis Topografi}

Hasil Topografi tanah pada daerah TPA Ngipik diberikan pada Gambar 2. Dari Gambar 2 dapat diketahui bahwa terdapat 2 timbunan sampah pada TPA Ngipik, dengan tinggi $10 \mathrm{~m}$ dan $12 \mathrm{~m}$. Dari hasil tersebut kemudian dibuatlah 5 pemodelan untuk mensimulasikan beban dinamis dengan menggunakan program bantu. 5 Pemodelan yang dilakukan tersebar pada 2 titik timbunan sampah di TPA Ngipik.

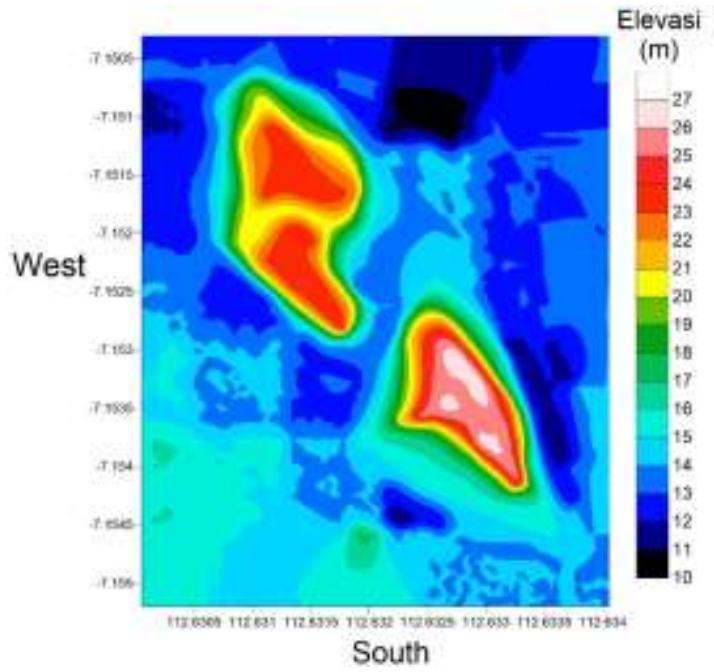

Gambar 2. Topografi TPA Ngipik

\subsection{Hasil Analisis Program Bantu Plaxis}

Dari pemodelan yang telah dilakukan, maka didapatkan cotoh hasil sebaran nilai shear strain pada timbunan sampah yang diberikan pada Gambar 3.

Dari 5 pemodelan yang dilakukan, terlihat bahwa nilai shear strain yang dihasilkan mempunyai nilai terbesar pada lapisan bawah timbunan. Hal ini diakibatkan karena ketika pemodelan dan input beban gempa, bagian bawah permukaan timbunan mengalami beban sendiri lebih besar dari bagian lain, sehingga jika ditambahkan beban gempa, maka nilai shear starin tertinggi juga ditemukan pada lapisan bawah permukaan timbunan. Sebaran nilai shear starin hasil pemodelan dengan Plaxis diberikan pada Gambar 4.

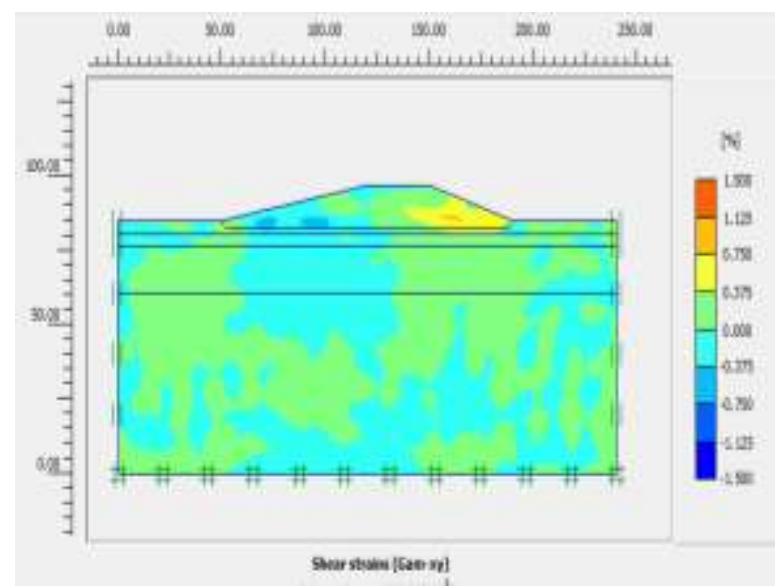

Gambar 3. Contoh Output Nilai Shear Strain Pada Program Bantu

Gambar 4 menunjukan hasil nilai shear strain dari plaxis. Nilai shear strain dari plaxis juga yang paling besar terletak pada bagian timur TPA Ngipik. Hal ini juga diakibatkan karena bagian timur TPA ngipik merupakan daerah dengan timbunan sampah yang lebih tinggi. Setelah itu, untuk melihat nilai gabungan dari hasil shear strain dengan mikrotremor dan hasil dari plaxis diberikan pada Gambar 5.

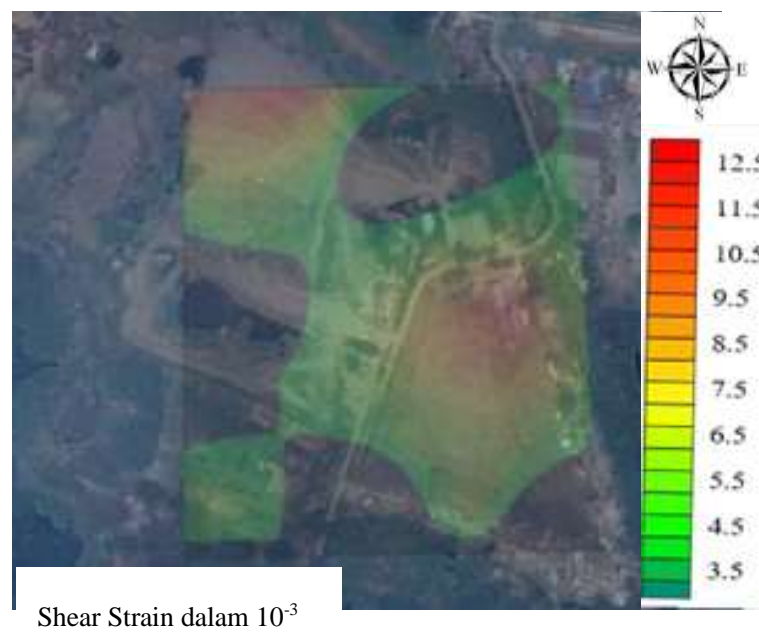

Gambar 4. Hasil nilai shear strain dari Plaxis

Dari hasil nilai shear strain yang dilakukan yaitu hasil mikrotremor dan analisis plaxis seperti pada Gambar 5. Nilai shear strain berkisar antara $3.5 \times 10^{-3}$ hingga $12.5 \times$ $10^{-3}$, daerah yang tidak diberikan zonasi dengan 
warna mempunyai nilai shear strain yang lebih kecil dari nilai tersebut. Nilai shear strain tinggi tersebar pada bagian timur dan barat laut TPA Ngipik. Sehingga daerah tersebut akan lebih rentan terhadap bahaya akibat gempa. Daerah dengan tingkat kerentaan yang lebih tinggi akan menngakibatkan persebaran lindi dan akan membahayakan bagi daerah sekitar. Hasil penelitian ini diharapkan menjadi mitigasi awal sehingga dijadikan acuan untuk pengambil keputusan jika akan dilakukan pengembangan di TPA Ngipik.

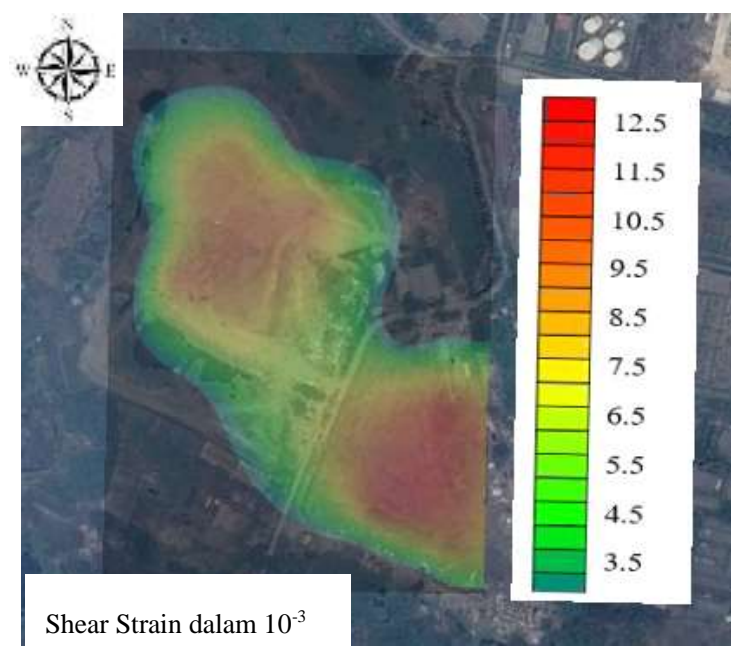

Gambar 5. Hasil nilai shear strain gabungan dari Plaxis dan Mikrotremor

\section{KESIMPULAN}

Kesimpulan yang dapat diambil dari penelitian ini adalah :

1. Tingkat kerentanan tanah tertinggi ditemukan pada daerah timur dan barat laut TPA ngipik dengan nilai $3.5 \times 10^{-3}$ hingga $12.5 \times 10^{-3}$.

\section{DAFTAR PUSTAKA}

[1] H. Kuncoro, G. A. J. Kartini, I. Meilano, and S. Susilo, "IDENTIFIKASI MEKANISME SESAR DI BAGIAN TIMUR PULAU JAWA DENGAN MENGGUNAKAN DATA GNSS KONTINYU 2010-2016," Semin. Nas. Geomatika, 2019, doi: 10.24895/sng.2018.3-0.1069.

[2] V. Zania, Y. Tsompanakis, and P. N. Psarropoulos, "Seismic distress and slope instability of municipal solid waste landfills," $J$. Earthq. Eng., 2008, doi: 10.1080/13632460701574605.

[3] Y. Nakamura, "Seismic vulnerability indices for ground and structures using microtremor," World Congr. Railw. Res., 1997.

[4] Y. Nakamura, T. Sato, and M. Nishinaga, "Local Site Effect of Kobe Based on Microtremor," Proc. Sixth Int. Conf. Seism. Zo. EERI, Novemb. 12-15, 2000/ Palm Springs. Calif., 2000.

[5] S. Nurlita Fitri, R. Asih Aryani Soemitro, D. Dewa Warnana, and N. Sutra, "Application of microtremor HVSR method for preliminary assessment of seismic site effect in Ngipik landfill, Gresik," in MATEC Web of Conferences, 2018, doi: 10.1051/matecconf/201819503017. 